\title{
PENINGKATKAN KETERAMPILAN BATTING MELALUI METODE PEMBEBANAN PADA ATLET BASEBALL
}

\author{
Norma Anggara ${ }^{1}$ \\ Angga Prananda Bakti ${ }^{2}$ \\ Universitas Lambung Mangkurat \\ Normaanggara11@gmail.com
}

\begin{abstract}
ABSTRAK
Penelitian ini bertujuan untuk mengetahui peningkatan keterampilan gerak batting melalui metode pembebanan pada atlet Baseball di club UPI Bandung. Penelitian ini menggunakan metode penelitian tindakan sebanyak dua siklus dengan rancangan kegiatan perencanaan, observasi, tindakan, dan refleksi. Sasaran dalam penelitian ini adalah mahasiswa yang tergabung dalam club baseball di UPI Bandung, sebanyak 24 atlet. Sumber data diperoleh melalui tes awal dan tes akhir keterampilan batting. Teknik analisis data yang digunakan dalam penelitian ini adalah deskriptif. Hasil penelitian menunjukkan bahwa melalui pendekatan kooperatif dari tes awal sampai ketesakhir. Rata- rata hasil keterampilan dari tes awal adalah 575 dan rata-rata nilai 23.95, hanya $30.26 \%$ dengan pendekatan pembebanan latihan baseball menjadi semakin meningkat yaitu nilai keseluruhan menjadi 980 dengan rata-rata nilai per individu 40.83 atau $51.57 \%$ pada Siklus I. Kemudian pada siklus II naik menjadi $70.33 \%$ atau lebih dari $70 \%$ atau lebih dari setengah dari jumlah sampel sudah dikatakan biasa melakukan gerakan batting dalam baseball dengan baik dan benar. Simpulan dari penelitian ini adalah metode latihan pembebanan yang berpengaruh positif dalam meningkatkan prestasi latihan atlet baseball, yang ditandai dengan peningkatan ketuntasan.
\end{abstract}

Kata kunci: Metode Pembebanan, keterampilan batting, baseball

\begin{abstract}
This research aims to determine the increase inbattingskills through the loading method in athletes Baseball club UPI Bandung. We use action research methods to the design as much as two-cycle with planning, observation, action, and reflection. The target in this research is the students in the baseball club in UPI Bandung, as many as 24 athletes. Sources of data obtained through the initial test and final test batting skills. Data analysis technique used in this research is descriptive. The results showed that through a cooperative approach from the initial test to the final test. The average result of the skill of the initial test was 575 and the average value is 23.95 , only $30.26 \%$ with a baseball workout loading approach becomes increasing value overall to be 980 with the average value per individual 40.83, or 51.57\% in Cycle I. Then on the second cycle increased to $80.33 \%$, or more than $80 \%$, or more than half of the usual number of samples has been said in the baseball batting movements properly. Conclusions from this research is the method of loading exercise has positive effects in increasing performance athlete baseball practice, characterized by increased completeness.
\end{abstract}

Keywords: Loading Method, of batting skill, baseball

Dipublikasikan Oleh :

UPT Publikasi dan Pengelolaan Jurnal

Universitas Islam Kalimantan Muhammad Arsyad Al-Banjari Banjarmasin 


\section{PENDAHULUAN}

Karakteristik Baseball dan softball merupakan cabang olahraga yang memerlukan unsur kecepatan dan ketepatan artinya unsur kecepatan dalam memutuskan, misalnya dalam teknik memukul atau batting, melempar atau throwing, fielding, base running dan pitching. Tepat dalam memukul, melempar dan pitching. Selain itu performa fisik juga mempengaruhi dalam penguasaan teknik yang bersifat intensitas tinggi, baseball termasuk olahraga yang didominasi anaerob. Sejalan dengan Bompa (1999), menyatakan bahwa prestasi olahraga dapat dicapai melalui pembinaan dan pelatihan yang baik dan benar yang bertujuan untuk meningkatkan performa fisik secara keseluruhan dan sesuai dengan karakteristik dari cabang olahraga tersebut. Hampir semua gerakan dalam baseball memiliki kompleksitas gerak yang tinggi, untuk itu atelt harus mempunyai kemampuan dan performa yang tinggi serta mempunyai bakat kekhususan dalam cabang olahraga.

Pada permainan baseball yang menjadi ciri khas adalah defensive dan offensive secara terpisah yang dilakukan seperti bergiliran. Pada saat pemain bertahan didominasi oleh seorang pitcher, jadi kalau seorang pitcher tidak mampu menyulitkan seorang pemukul maka dengan demikian pertahanan suatu tim menjadi gagal dalam mempertahankan run atau poin. Sedangkan pada saat offensive atau menyerang hampir seluruh pemain mengerahkan teknik dan kekuatannya untuk bisa mengantisipasi bola yang disajikan oleh seoarang pitcher lawan, sehingga penampilan pada saat offensive mampu meraih poin sebanyak-banyaknya.

Latihan harus dilakukan secara sistematis dan berulang-ulang dengan penambahan beban yang progresif dan individual dan dalam jangka waktu yang lama, hal ini bertujuan untuk memperbaiki sistem serta fungsi fisiologis dan psikologis tubuh agar pada saat melakukan aktivitas olahraga dapat mencapai kondisi yang optimal. Selain itu, olahraga pada jaman sekarang sudah merupakan kebutuhan dan menjadi sebuah kultur serta pelaku olahraga pun harus bersikap kritis dan ilmiah. Pada penerapan ilmu biomekanika gerak pada teknik memukul ini menjadi sangat penting karena menurut pengamatan penulis di Indonesia belum ada yang meneliti tentang objektivitas hasil teknik memukul dalam permainan baseball. Dengan menggunakan bantuan software analysis dan swing analysis sensor diharapkan akan membuka khazanah baru dalam dunia baseball ditanah air yang selama ini hanya menggunakan pengamatan dan video sehingga hasilnya kurang akurat dalam mengukur variabel speed bat, hand speed dan time to impact.

Berdasarkan penjelasan latar belakang diatas, penulis ingin menganalisis mengenai pengaruh metode latihan (heavy bag swing stroke dan horizontal dumble swing) terhadap peningkatan keterampilan batting (speed bat, hand speed dan time to impact).

\section{METODE}

Metode penelitian yang digunakan adalah metode Penelitian Tindakan (Action Research).Pelaksanaan penelitian melibatkan rekan sebagai kolaborator dan guru kelas, kemudian peneliti sebagai pelaksana tindakan. Dengan desain penelitian Kemmis dan taggart yang meliputi: 1) perencanaan, 2) pelaksanaan, 3) pengamatan, dan 4) refleksi.

Berikut model Stephen Kemmis dan Mc Taggart yang mana menggunakan sistem spiral cyclical refleksi diri. Seperti pada gambar berikut :

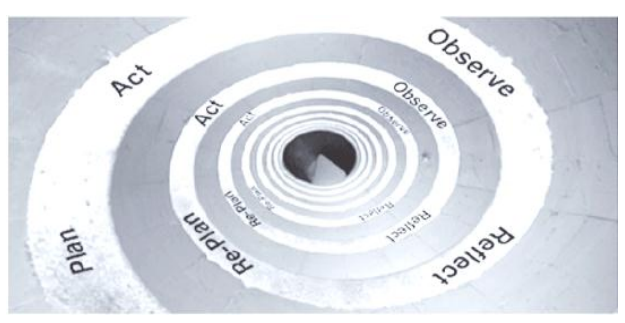

Gambar 1. Stephen Kemmis dan Mc Taggart spiral cyclical

Sumber: Stephen Kemmis, Robin dan Mc Taggart, The Action Research Planner Doing Critical Participatory Action Research. (Springer, 2014:19).

Peneliti membuat 2 desain latihan yang telah dikembangkan, Berdasarkan observasi awal peneliti di club baseball UPI Bandung terdapat fokus masalah yaitu upaya peningkatan keterampilan batting melalui metode pembebanan pada atlet baseball. Sehingga peneliti melakukan penelitian action research. Penelitian ini dilakukan 2 siklus untuk mendapatkan hasil belajar gerak dasar lari jarak pendek sesuai kriteria nilai yang dibutuhkan yaitu $80 \%$.

Dipublikasikan Oleh :

UPT Publikasi dan Pengelolaan Jurnal

Universitas Islam Kalimantan Muhammad Arsyad Al-Banjari Banjarmasin 


\section{HASIL DAN PEMBAHASAN}

Hasil tes awal keterampilan batting dalam baseball

Berdasarkan evaluasi hasil penilaian keterampilan batting melalui metode pembebanan pada atlet baseball yang dilakukan oleh peneliti dapat disajikan dalam klasifikasi sebagai berikut:

Persentase keberhasilan $=23.95 \%$

Persentase kegagalan $\quad=30.26 \%$

Berdasarkan hasil pengamatan pada tes awal tentang kegiatan latihan secara keseluruhan, pelatih telah melakukan kegiatan latihan secara ideal, akan tetapi ada catatan dari kolaborator yaitu peneliti harus lebih memperhatikan kondisi kelas ketika atlet mengikuti latihan agar lebih tertib dan teratur supaya tercapai tujuan keterampilan Selain itu, peneliti harus lebih kreatif dalam menyajikan permainan sehingga lebih bervariasi dan dapat memberikan motivasi kepada atlet terutama mengenai bagaimana cara membangkitkan semangat latihan atlet

Gerakan memukul adalah teknik sulit dalam permainan ini yang mengharuskan bisa memukul bola hasil lemparan pitcher lawan yang tidak diketahui arah, jenis bola dan kecepatanya, dan dituntut bisa berhasil melakukan hit (memukul), save on base, memajukan dan memasukkan rekan tim menjadi point. Ada beberapa indikator penunjang keberhasilan dalam melakukan teknik memukul yang dapat dilakukan dalam proses latihan, diantaranya adalah: Kepala, Lengan, Bahu, Mata, Pinggang, Paha, Kaki, Perpindahan Berat dan Power (Transfer weight power), Mental Imagery.

A. Kepala dan Mata

1) Kepala dan mata memandang pada pergerakan pitcher dan lepas-nya bola dari tangannya dengan relaks sampai ke sweet spot strike zone.

2) Perhatikan bola ampe masuk dalam zona pukulan untuk di adjust (ambil keputusan untuk dipukul).

B. Lengan

1) Untuk lead arm (kiri untuk pemukul kanan) sebaliknya, agar mengarahkan bat ke bola saat memasuki sweet spot) dengan posisi lengan rileks dengan menyimpan sekitar $20 \%$ dari tenaga / power lengan yang di miliki untuk melakukan persiapan (Triger the Swing) berbarengan dengan mendaratkan langkah sebagai (pivot landing step early)

2) Untuk tangan kanan sebagai power arm, memukul bola dengan bat dengan mengupayakan jalur ayuan bat memotong (cut down the swing)sehingga menghasilkan putaran bola ysng berbalik (back spin) atau pun bisa dengan datar merata.

3) Pergelangan tangan mengarah tetap ke atas dan mengusahakan tidak berputar atau pun melipat sebelum perkenaan dengan bola,karena pergelangan tangan tersebut akan berpengaruh untuk mendorong bola saat perkenaan (slap the ball) sehingga terjadi tumbukan sempurna.

c. Bahu

Bahu tetap sejajar lurus pada posisi awal (Stance) dan penurunan perubahan sudut bahu akan terjadi se cara normal sesuai dengan arah ayunan bat dengan (Down Swing level) agar tidak merubah posisi perkenaan (Point of Hitting) pada titik pukul utama (Sweet Spot Hiting Zone)

d. Koordinasi Mata

Kedua mata melihat dengan jelas selalu kearah pitcher untuk memastikan (Realease Pitching Point) untuk meihat jenis dan putaran bola (Spin) dan alur lintasan bola sampai pada titik pukul utama (Sweet Spot Hiting Zone) dan mengambil keputusan untuk memukul (Adjust The Ball quicly) dengan arah ayunan bat dengan (Down Swing level) d dan mata tetap melihat terus sampai dengan perkenaan bola dengan bat agar tidak merubah posisi perkenaan (Point of Hitting) pada titik pukul utama (Sweet Spot Hiting Zone)

e.Transfer Weight dan Power

Latihan adalah sangat penting dalam pengembangan atlet, yang harus terdiri dari sekedar mengangkat beban dengan memiliki tujuan tertentu atau rencana.Tujuan dari metode pelatihan atau teknik harus ke mempersiapkan atlet saat tes kompetisi yang ideal dari kemampuan mereka, keterampilan, dan kesiapan psikologis.Untuk mencapai hasil terbaik, atlet harus terkena program perencanaan-periodisasi, atau variasi Sport- dan fase-spesifik pelatihan.Periodisasi jangka menekankan yang memiliki sifat unik Periodisasi Kekuatan, konsep utamanya adalah latihan kekuatan.

Latihan lebih dari sekedar mengangkat sebanyak berat karena mungkin setiap hari tanpa memperhatikan tujuan dari fase pelatihan khusus. Dengan demikian, ia menawarkan suatu metodologi dan Konsep untuk mengikuti dalam mencapai tujuan pelatihan Anda untuk kompetisi.

Dipublikasikan Oleh :

UPT Publikasi dan Pengelolaan Jurnal

Universitas Islam Kalimantan Muhammad Arsyad Al-Banjari Banjarmasin 
Proses gerak tidak begitu saja terjadi pada diri manusia. Karena untuk dapat melakukan suatu gerakan pada tubuh perlu proses, mulai dari adanya rangsangan, dikelola dalam pikiran, dan kemudian ditampilkan melalui respon yang dilakukan oleh tubuh. Tujuan akhir dari pembelajaran gerak adalah kemampuan penguasaan keterampilan. Keterampilan seseorang dalam tugas gerak tertentu akan menentukan seberapa besar kemampuan orang tersebut dalam menyelesaikan tugas yang diberikan dengan derajat keberhasilan yang tinggi. Untuk sampai pada tujuan akhir tersebut diperlukan pengetahuan yang mendasar tentang bagaimana keterampilan bisa dihasilkan serta faktor apa saja yang berperan dalam gerakan itu? Pertama yang harus dikuasai adalah mempelajari bagaimana gerakan itu bisa berlangsung. Kedua berhubungan dengan syarat-syarat apa saja yang harus dipenuhi agar keterampilan gerak dapat dicapai dengan baik. Keterampilan gerak dapat dicapai dengan cara latihan atau dengan berbagai keterlibatan dengan berbagai pengalaman.

Pada dasarnya proses belajar gerak memiliki prinsip sama dengan proses belajar pada umumnya. Istilh belajar gerak juga sering disebut sebagai belajar motorik. Para ahli seperti William Edwards mengatakan bahwa : "Learning is not attained by chance, it must be sought for with passion and attended to with diligence. Yang dimaksud Belajar tidak dicapai secara kebetulan, untuk itu harus dicari dengan semangat dan diiringi, dengan ketekunan. Perkembangan gerak dasar fundamental (movement ability) akan mengalami perubahan atau kemajuan ke arah yang lebih baik secara bertahap. Hal tersebut tergantung pada tingkat kematangan dan banyaknya pengalaman yang dialami anak, seperti melakuakan suatu keterampilan gerakan cabang olahraga, dan juga memberikan rangsangan atau dorongan dalam setiap pembelajarannya.

Gerak dasar fundamental merupakan suatu gerakan dasar yang perkembangannya dapat sejalan dengan pertumbuhan tubuh dan tingkat kematangan pada anak-anak. Gerakan Lokomotor adalah gerakan berpindah tempat dari satu ketempat lain, seperti berjalan dan berlari. Sedangkan gerak non lokomotor adalah gerakan yang berporos pada sumbu dibagian tubuh tertentu, seperti memutar lengan, mengayunkan kaki, dan memutar togok. Sedangkan gerakan manipilatif adalah gerakan memainkan objek tertentu dengan menggunakan bagian tubuh tertentu, seperti memainkan bola dengan tangan, kaki, atau bagian tubuh lainnya

Hasil tes akhir siklus I keterampilan batting dalam baseball

Berdasarkan evaluasi hasil penilaian gerak latihan batting pada latihan baseball yang dilakukan oleh peneliti dapat disajikan dalam klasifikasi sebagai berikut:

Persentase keberhasilan $=51,57 \%$

Pesentase kegagalan $\quad=40,83 \%$

Berdasarkan hasil pengamatan pada hasil tes akhir siklus I tentang kegiatan latihan secara keseluruhan, pelatih telah melakukan kegiatan latihan secara ideal, akan tetapi ada catatan dari kolaborator yaitu peneliti harus lebih memperhatikan kondisi lapangan ketika atlet mengikuti permainan agar lebih tertib dan teratur supaya tercapai tujuan latihan. Selain itu, peneliti harus lebih kreatif dalam menyajikan permainan sehingga lebih bervariasi dan dapat memberikan motivasi kepada atlet terutama mengenai bagaimana cara membangkitkan semangat latihan atlet. Pencapaian latihan belum tercapai hingga 80\% maka akan dilanjutkan dengan siklus ke II.

\section{Hasil tes akhir siklus II gerak keterampilan batting pada baseball}

Berdasarkan evaluasi hasil penilaian keterampilan batting dalam baseball yang dilakukan oleh peneliti dapat disajikan dalam klasifikasi sebagai berikut:

Persentase keberhasilan $=80.35 \%$

Pesentase kegagalan $\quad=18.65 \%$

Berdasarkan hasil pengamatan pada siklus II tentang kegiatan latihan keterampilan secara keseluruhan, pelatih telah melakukan kegiatan latihan secara ideal, akan tetapi ada catatan dari kolaborator yaitu peneliti harus lebih memperhatikan kondisi lapangan ketika atlet mengikuti permainan agar lebih tertib dan teratur supaya tercapai tujuan latihan. Selain itu, peneliti harus lebih kreatif dalam menyajikan permainan sehingga lebih bervariasi dan dapat memberikan motivasi kepada atlet terutama mengenai bagaimana cara membangkitkan semangat latihan para atlet. Berdasarkan hasil penilaian keterampilan latihan batting secara keseluruhanevaluator, dan hasil dari tes akhir pada siklus I hingga siklus II, terjadi perubahan yang signifikan.meningkatnya keterampilan gerak latihan batting pada baseball di clup baseball UPI Bandung yang telah dilakukan oleh.Dapat dilihat dari hasil perhitungan dari data tes akhir siklus I dan II yaitu sebagai berikut

Dipublikasikan Oleh :

UPT Publikasi dan Pengelolaan Jurnal

Universitas Islam Kalimantan Muhammad Arsyad Al-Banjari Banjarmasin 




Gambar 2. Diagram batang

Hasil keterampilan latihan batting dalam baseball Siklus I dan Siklus II

\begin{tabular}{|l|l|l|l|l|l|l|}
\hline \multirow{2}{*}{ No } & \multirow{2}{*}{ Kategori } & \multirow{2}{*}{ Nilai kelulusan } & Siklus I & \multicolumn{2}{|l|}{ Siklus II } \\
\cline { 4 - 7 } & & & F & \% & F & $\%$ \\
\hline 1. & Lulus & $>60$ & $\mathbf{1 5}$ & $\mathbf{6 2 . 5 0}$ & $\mathbf{2 0}$ & $\mathbf{8 3 . 3 3}$ \\
\hline 2. & Tidak lulus & $<60$ & $\mathbf{9}$ & $\mathbf{3 7 . 5 0}$ & $\mathbf{4}$ & $\mathbf{1 6 . 6 7}$ \\
\hline$\sum$ & & $\mathbf{2 4}$ & $\mathbf{1 0 0}$ & $\mathbf{2 4}$ & $\mathbf{1 0 0}$ \\
\hline
\end{tabular}

Tabel 1. Hasil pencapaian penilaian latihan batting dalam baseball

\begin{tabular}{|c|l|l|}
\hline Nilai & Makna & Keterangan \\
\hline $80 \%$ & valid & Latihan Berhasil \\
\hline $65-79 \%$ & Cukup Valid & Latihan Berhasil \\
\hline $45-59 \%$ & Kurang Valid & Latihan Tidak Berhasil \\
\hline $30-39 \%$ & Tidak Valid & Latihan Tidak Berhasil \\
\hline$<29 \%$ & Tidak Valid & Latihan Tidak Berhasil \\
\hline
\end{tabular}

Tabel 2. Analisis Persentase Hasil Evaluasi Oleh Subyek Uji Coba

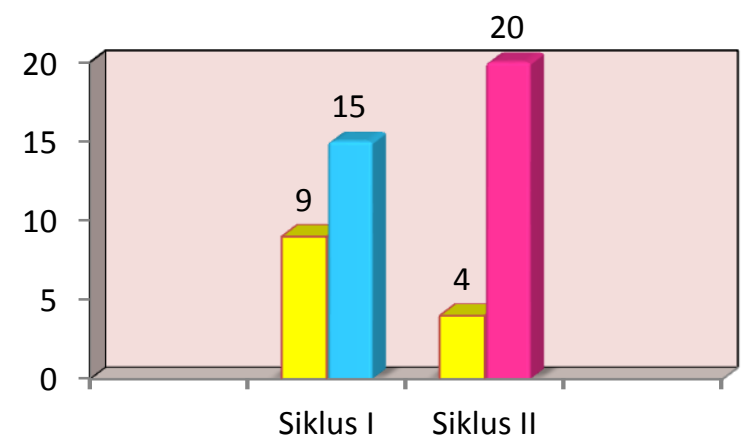

Gambar 3. Diagram batang Hasil keterampilan latihan batting dalam baseball Siklus I dan Siklus II

Dipublikasikan Oleh :

UPT Publikasi dan Pengelolaan Jurnal

Universitas Islam Kalimantan Muhammad Arsyad Al-Banjari Banjarmasin 


\section{PENUTUP}

\section{Kesimpulan}

Hasil penelitian terlihat bahwa proses latihan dengan kegiatan metode pembebanan, dapat merangsang kemampuan keterampilan siswa. Sehingga dalam proses pembelajaran ini atlet lebih aktif dalam latihan.

\section{Saran}

Dengan kegiatan proses latihan yang baik dapat meningkatkan dan mengembangkan keterampilan, mengembangkan skill dan mengembangkan sikap kompetitif yang sangat penting sebagai nilai-nilai yang harus ditanamkan pada atlet yang tentunya berguna untuk menghadapi suatu permasalahan yang terjadi yang akan datang.

\section{REFERENSI}

\section{Buku Penulis 1}

Hidayat, Imam.(2003) Biomekanika: Pendekatan dalam Sistem Pembelajaran Gerak. Bandung: PPS UPI,

\section{Buku Penulis 2}

Widiastuti,(2011) Tes dan Pengukuran Olahraga, Jakarta: PT. Bumi Timur Jaya,

\section{Buku Penulis 3}

Tangkudung, James dan Wahyuningtyas, Puspitorini.(2012)Kepelatihan Olahraga Edisi II. Jakarta:

\section{Cerdas Jaya}

\section{Artikel Jurnal / Ensiklopedi}

1. Alderson, Sandy., Antonetti, Chris., Bernabe, Sam., Dipoto, Jerry., Gorman, Brian., Mozeliak, John., Ryan, Terry., Schuerholz, John and Torre, Joe.(2015) Official Playing Rules Committee. The Office of the Commissioner of Baseball,.

2. Edwards, William.(2010) Motor Learning and Control From Theory to Practice. California State University:. Wadsworth .

3. Kemmis, Stephen, in Geoffrey E. Mills.(2010) Action Research: A Guide For The Teacher Researcher (New Jersey: Prentice-Hall,

4. Kusumah Negara Jajat D. (2009) Analisis Biomekanika Softball-Baseball. Jakarta: Jurnal IPTEK Olahraga KONI Pusat,

5. McGinnis,(2013) Peter M. Biomechanics of Sport and Exercise. State University of New York, College at Cortland: Human Kinetics 3rd Edition,.

6. Russel, Dan. (2010)Swing Weights of Baseball and Softball Bats. The Physics Teachers. Vol 48: 471-474,

7. Sawicki, Gregori S., Hubbard Mont., Stronge William J.(2003) How to Hit Home Runs: Optimum Baseball Bat Swing Parameters for Maximum Range Trajectories. American Journal of Physiology: Vol 71(11): 1152-1162.

8. Christian M.(1995) Et al. Hitting a Baseball: A Biomechanical Description. Journal of Orthopaedic and Sport Physical Therapy: Vol 22(3): 193-201, 